\title{
Perfil lipídico da gordura intramuscular de cortes e marcas comerciais de carne bovina
}

\section{Angélica Pereira dos Santos Pinho ${ }^{1}$, Júlio Otávio Jardim Barcellos ${ }^{2}$, Vanessa Peripolli ${ }^{1}$, Liris Kindlein ${ }^{3}$, Juliana Rosa de Araújo ${ }^{4}$, Dari Celestino Alves Filho ${ }^{5}$}

${ }^{1}$ Curso de Pós-Graduação em Zootecnia, Faculdade de Agronomia - UFRGS.

2 Departamento de Zootecnia, Faculdade de Agronomia - UFRGS. Pesquisador CNPq.

${ }^{3}$ Faculdade de Veterinária - UFRGS.

${ }^{4}$ Curso de Graduação em Medicina Veterinária - UFRGS.

5 Departamento de Zootecnia, Universidade Federal de Santa Maria - UFSM.

RESUMO - O trabalho foi realizado para caracterizar a gordura intramuscular dos cortes contrafilé, picanha e costela de seis marcas comerciais (A, B, C, D, E e F) de carne bovina comercializadas no município de Porto Alegre, Rio Grande do Sul. As amostras foram coletadas em uma rede de hipermercados. As marcas A e B foram associadas a animais de raças britânicas, as marcas C e D de animais de raças européias produzidos em sistema convencional e orgânico, respectivamente, e provenientes do Uruguai e as marcas E e F de animais sem raça definida e sistema de alimentação não identificado, obtidas em um frigorífico regional e em uma rede de hipermercados, respectivamente. As amostras foram desossadas, moídas, embaladas a vácuo e armazenadas em temperatura de resfriamento até o momento das análises. Em cada amostra foram realizadas a extração dos lipídios e a identificação dos ácidos graxos. O delineamento experimental foi inteiramente casualizado, com arranjo fatorial $6 \times 3$ e os dados analisados pelo procedimento GLM do aplicativo computacional SAS. Não houve interação significativa entre cortes e marcas para o perfil lipídico dos cortes comerciais. O percentual lipídico foi de 0,95; 3,01 e 0,97\% nos cortes contrafilé, costela e picanha, respectivamente. A costela apresentou maior percentual de ácidos graxos (AG) saturados e maior estimativa da $\Delta^{9}$ desaturase a partir do C16:0 e C18:0. O maior percentual de C18:2 cis-9, trans 11, ácido linoleico conjugado, CLA, n-6 e n-3 foi encontrado na picanha. A marca F apresentou maior grau de saturação e a marca D, maior valor de ácidos graxos poliinsaturados, relação poliinsaturados/saturados e trans18 e menor valor de ácidos graxos saturados. Houve interação significativa entre corte e marca para o conteúdo de CLA, sendo o maior conteúdo encontrado no contrafilé da marca F. As características da gordura intramuscular da carne bovina dependem do corte e da marca comercial.

Palavras-chave: ácidos graxos saturados, ácidos graxos insaturados, contrafilé, costela, picanha

\section{Lipid profile of intramuscular fat in meat cattle cuts of commercial brands}

\begin{abstract}
The objective of this work was to characterize the intramuscular fat of short loin, ramp loin and rib and six commercial brands (A, B, C, D, E and F) of beef commercialized in Porto Alegre, Rio Grande do Sul. Samples were collected from a supermarket chain. The brands A and B were associated with British animals breeds, the brands C and D were from European animals breeds produced in conventional and organic system, respectively, from Uruguay, while the brands $\mathrm{E}$ and F were derived from non specific breed and unidentified feeding system, obtained in a slaughterhouse and a regional chain of supermarkets, respectively. The samples were deboned, ground, vacuum packed and stored in cooling temperature until the moment of analysis. In each sample were extracted lipids and fatty acids were identified. The experimental design was a completely randomized, with a $6 \times 3$ factorial arrangement and analyzed by the GLM procedure of SAS computing application. Regarding lipid profile no significant interaction were found among cuts and brands of commercial cuts. The lipid percentage was $0.95 ; 3.01$ and $0.97 \%$ in short loin, ribs and ramp loin cuts. Rib presented the greatest percentage of saturated fatty acids (FA) and the greatest estimate of $\Delta^{9}$ desaturase from C16:0 and C18:0. The highest percentage of C18:2 cis-9, trans 11, conjugated linoleic acid, CLA, n-6 and n-3 was found in ramp loin. Brand F showed a higher degree of saturation, while the brand D showed higher polyunsaturated fatty acids, polyunsaturated/saturated ratio and trans18 and the lowest saturated fatty acids. There was a significant interaction between cuts and brands for the content of CLA, with the highest content found in the short loin of brand F. The characteristics of intramuscular beef fat depending on the cuts and the commercial brands.
\end{abstract}

Key Words: insaturated fatty acids, ribs, ramp loin, saturated fatty acids, short loin 


\section{Introdução}

Com a melhora no padrão de vida da população brasileira, houve mudanças no padrão alimentar, com aumento no consumo de proteínas de origem animal (FNP, 2008). Entretanto, o consumidor, mais preocupado e exigente com a saúde, tem sido mais criterioso na escolha dos alimentos e tem se atentado às informações nutricionais e ao perfil lipídico dos alimentos.

O consumo de carne bovina sofre restrições por causa da comum associação dos ácidos graxos saturados ao desenvolvimento de problemas na saúde humana (Nuernberg et al., 2005). A gordura intramuscular da carne bovina é composta basicamente por 20 ácidos graxos, com 16 a 18 átomos de carbono, de diferentes graus de saturação, entre eles, os ácidos graxos oleico, palmítico, esteárico, linoleico, palmitoleico e mirístico, que constituem 92\% do total. Ou seja, cerca de $45 \%$ de ácidos graxos saturados, 50\% de monoinsaturados, 5\% de cadeia ímpar e pequenas quantidades de ácidos graxos poliinsaturados, como o ácido linoleico conjugado. Além disso, na carne ou nos produtos cárneos são encontrados ácidos graxos do tipo trans, que podem ser gorduras formadas no processo de hidrogenação artificial feito nas indústrias, em que sob alta pressão e temperatura, moléculas de hidrogênio são adicionadas às cadeia carbonadas (Di Marco, 2007), ou por meio da biohidrogenação que acontece no rúmen (Wood et al., 2008).

Com a mudança do comportamento do consumidor, os segmentos fornecedores de carne bovina passaram a desenvolver programas de qualidade, que resultaram em diversas marcas de carnes e de cortes especializados. No entanto, nem sempre um produto com marca ou com algum grau de certificação dispõe de informações nutricionais suficientes para permitir ao consumidor uma escolha segura.

Assim, realizou-se este trabalho com o objetivo de avaliar e caracterizar a gordura intramuscular de cortes e marcas de carne bovina disponíveis no mercado local.

\section{Material e Métodos}

As amostras de contrafilé (longissimus), costela (intercostal) e picanha (biceps femoris) de seis marcas comerciais foram coletadas em uma rede de hipermercados do município de Porto Alegre, Rio Grande do Sul, no período de dezembro de 2007 a junho de 2008.

As marcas comerciais A e B foram associadas a animais de raças britânicas, Angus e Hereford, ou seus cruzamentos com no mínimo 50\% de sangue europeu, Braford ou Brangus (3/8 sangue zebu), abatidos em idade jovem (com 0 a 6 dentes e peso entre 190 a $220 \mathrm{~kg}$ ), machos e fêmeas que receberam suplementação de grãos, enquanto as amostras das marcas comerciais C e D foram oriundas de animais de raças europeias, abatidos em idade jovem e provenientes do Uruguai. Os bovinos da marca C foram produzidos em sistema convencional (suplementação de grãos) e as amostras da marca $\mathrm{D}$ foram oriundas de animais produzidos em sistema orgânico (criados e terminados em pastagens).

As amostras da marca $\mathrm{E}$ e $\mathrm{F}$ foram oriundas de animais sem raça ou idade definida e sistema de terminação não identificado. A marca $\mathrm{E}$ foi obtida em um frigorífico regional e a marca F em uma rede de hipermercados. As amostras foram coletadas de cortes mantidos em temperaturas de resfriamento, desossados em períodos de 24 a 48 horas, embalados a vácuo em filme flexível de alta barreira ao oxigênio e termoencolhível (cryovac) e com validade de 60 dias após a desossa. As peças foram transportadas em temperatura de resfriamento, protegidas da luz. No laboratório, a gordura externa das amostras foi removida e uma porção de $2,5 \mathrm{~cm}$ do tecido muscular de cada corte (costela, contrafilé ou picanha) foi extraída (moída) e armazenada a $-18^{\circ} \mathrm{C}$ para posterior análise (após 30 dias).

As análises laboratoriais de perfil de ácidos graxos foram realizadas no Laboratório de Nutrição e Crescimento Animal da Escola Superior de Agricultura Luiz de Queiroz (ESALQ)/USP, Piracicaba, São Paulo.

Nas amostras descongeladas, foi realizada a extração dos lipídios (Hara \& Hadin, 1978). Os percentuais de lipídios totais foram de 0,$95 ; 3,01$ e $0,97 \%$ para contrafilé, costela e picanha, respectivamente. Posteriormente, os ácidos graxos foram transmetilados conforme a técnica detalhada por Christie (1982) e uma alíquota de $1 \mu \mathrm{L}$ dos lipídios transmetilados foi injetada em cromatógrafo a gás, modelo Focus CG-Finnigan, com detector de ionização de chama, coluna capilar CP-Sil 88 (Varian), com $100 \mathrm{~m}$ de comprimento por $0,25 \mu \mathrm{m}$ de diâmetro interno e $0,20 \mu \mathrm{m}$ de espessura do filme. O gás de arraste utilizado foi o hidrogênio, numa vazão de $1,8 \mathrm{~mL} / \mathrm{min}$. O programa de temperatura do forno do cromatógrafo foi o seguinte: início com $70^{\circ} \mathrm{C}$ e tempo de espera de 4 minutos, posteriormente elevado a $175^{\circ} \mathrm{C}$ $\left(13^{\circ} \mathrm{C} / \mathrm{min}\right)$ e tempo de espera $27 \mathrm{~min}$, após a $215^{\circ} \mathrm{C}\left(4^{\circ} \mathrm{C} / \mathrm{min}\right)$ e tempo de espera $9 \mathrm{~min}$ e, finalmente, aumento de $7^{\circ} \mathrm{C} / \mathrm{min}$ até $230^{\circ} \mathrm{C}$, permanecendo por $5 \mathrm{~min}$, totalizando $65 \mathrm{~min}$. A temperatura do vaporizador foi de $250^{\circ} \mathrm{C}$ e a do detector de $300^{\circ} \mathrm{C}$. A identificação dos ácidos graxos foi feita pela comparação dos tempos de retenção com os obtidos com ésteres metílicos de amostras padrão e a quantificação das porcentagens dos ácidos graxos foi realizada utilizando o software-Chromquest 4.1 (Thermo Electron, Italy). 
O delineamento experimental foi inteiramente casualizado em arranjo fatorial $6 \times 3$ (seis marcas $\times$ três cortes), totalizando 7 repetições por tratamento. Os dados foram analisados pelo procedimento GLM do programa estatístico SAS (2002).

O modelo estatístico adotado na análise da variância foi:

$$
Y_{i j k}=\mu+C_{i}+M_{j}+C_{i} B_{i j}+\epsilon_{i j k} \text {, }
$$

em que: $\mathrm{Y}_{\mathrm{ijk}}=$ variáveis dependentes; $\mu$ = média geral de todas as observações; $\mathrm{CB}_{\mathrm{i}}=$ efeito do corte de ordem "i"; $\mathrm{MB}_{\mathrm{j}}=$ efeito de marca de ordem “j” (tratamento); $\mathrm{CB}_{\mathrm{i}} \mathrm{MB}_{\mathrm{j}}=$ interação entre efeito do corte de ordem "i” e efeito de marca de ordem “j” ; $\in_{\mathrm{ijk}}=$ erro aleatório de ordem residual.

\section{Resultados e Discussão}

Os resultados médios de lipídios totais para os cortes foram 0,95; 3,01 e 0,97\% para contrafilé, costela e picanha, respectivamente. Entre os parâmetros do perfil lipídico, somente para o conteúdo de CLA houve interação significativa entre cortes e marcas, portanto, para os demais, serão discutidos apenas os efeitos principais de cortes e marcas. Os ácidos graxos de cadeia média de maior concentração em todos os cortes foi o ácido palmítico (C16:0), cujo maior valor foi observado na costela (25,72\%) e no contrafilé (25,57\%), ambos com valores superiores ao da picanha (22,14\%) (Tabela 1).

A maioria dos ácidos graxos de cadeia média, entre C12C16, varia significativamente com o corte avaliado. Foram observadas diferenças significativas $(\mathrm{P}<0,05)$ para os ácidos graxos láurico (C12:0), mirístico (C14:0), isomirístico (C14:0iso), pentadecanoico (C15:0), isopentadecanoico (C15:0iso), antpentadecanoico (C15:0ant), palmítico (C16:0) e isopalmítico (C16:0iso).

A costela foi o corte com maior participação percentual de ácidos graxos de cadeia média, contudo, não diferiu do contrafilé. Na análise dos ácidos graxos saturados C12:0 e C16:0iso, também não diferiu significativamente da picanha $(0,082 \times 0,073$ e $0,330 \times 0,276 \%)$. A explicação para os maiores teores de ácidos graxos na costela pode ser a maior variabilidade de gordura. Em estudo com avaliação de 50 músculos de bovinos de corte adultos, Lawrie (2005) encontrou a maior variabilidade $(18,1 \%)$ de gordura na costela. Por outro lado, o ácido graxo C16:0 foi encontrado em maiores percentuais nos cortes costela e contrafilé. A preocupação com a grande quantidade desse ácido graxo na gordura da carne é com o aumento do colesterol sanguíneo (Banskalieva et al., 2000) ou sua concentração total no plasma em forma de LDL (colesterol ruim) (Beorlegui, 2004).

Neste trabalho, esperava-se encontrar grandes variações entre as marcas comerciais, pois as amostras são oriundas de diversos sistemas de terminação, idade de terminação, grau de acabamento, sexo, ingredientes de dietas e grupos genéticos, conforme descreveram Mulvihill (2001), Nürnberg et al. (2005) e Wood et al. (2008).

$\mathrm{Na}$ análise dos percentuais de ácidos graxos de cadeia curta e média, observou-se que o ácido graxo de cadeia média mais presente em todas as marcas foi o ácido palmítico (C16:0), entretanto não foi encontrada diferença $(\mathrm{P}>0,05)$ entre as marcas avaliadas (Tabela 2). Foram observadas diferenças significativas $(\mathrm{P}<0,05)$ na porcentagem dos ácidos graxos láurico (C12:0), mirístico (C14:0), isomirístico (C14:0iso), pentadecanoico (C15:0), isopentadecanoico (C15:0iso), ant-pentadecanoico (C15:0ant) entre as marcas analisadas.

A marca D apresentou os menores teores do ácido mirístico (C14:0) (1,77\%), embora não tenha diferindo da marca A. French et al. (2003) relataram que o ácido graxo mais indesejável seria o ácido mirístico, principalmente pelos danos causados pelo aumento do colesterol ruim (LDL). Esse menor teor de ácido mirístico na marca D (orgânica)

Tabela 1 - Composição percentual em ácidos graxos de cadeia curta e média da carne bovina

\begin{tabular}{lrrr}
\hline Ácido graxo & \multicolumn{3}{c}{ Corte } \\
\cline { 2 - 4 } & Contrafilé & Costela & Picanha \\
\hline C10:0 & $0,049 \pm 0,003$ & $0,054 \pm 0,003$ & $0,045 \pm 0,002$ \\
C12:0 & $0,069 \pm 0,004 \mathrm{~b}$ & $0,082 \pm 0,003 \mathrm{a}$ & $0,073 \pm 0,003 \mathrm{ab}$ \\
C14:0 & $2,340 \pm 0,110 \mathrm{~b}$ & $2,910 \pm 0,100 \mathrm{a}$ & $2,210 \pm 0,090 \mathrm{~b}$ \\
C14:0iso & $0,085 \pm 0,008 \mathrm{~b}$ & $0,145 \pm 0,007 \mathrm{a}$ & $0,097 \pm 0,006 \mathrm{~b}$ \\
C15:0 & $0,498 \pm 0,031 \mathrm{~b}$ & $0,738 \pm 0,030 \mathrm{a}$ & $0,564 \pm 0,025 \mathrm{~b}$ \\
C15:0iso & $0,260 \pm 0,017 \mathrm{~b}$ & $0,435 \pm 0,016 \mathrm{a}$ & $0,276 \pm 0,013 \mathrm{~b}$ \\
C15:0ant & $0,226 \pm 0,020 \mathrm{~b}$ & $0,274 \pm 0,016 \mathrm{~b}$ \\
C16:0 & $25,570 \pm 0,41 \mathrm{a}$ & $27,720 \pm 0,019 \mathrm{a}$ & $22,140 \pm 0,32 \mathrm{~b}$ \\
C16:0iso & $0,223 \pm 0,019 \mathrm{~b}$ & $0,330 \pm 0,018 \mathrm{a}$ & $0,276 \pm 0,015 \mathrm{ab}$ \\
Ć16:1c9 & $3,420 \pm 0,15$ & $3,300 \pm 0,14$ & $3,710 \pm 0,12$ \\
Ácidos graxos cadeia curta & $0,049 \pm 0,003$ & $0,054 \pm 0,003$ & $0,045 \pm 0,002$ \\
Ácidos graxos cadeia média & $33,250 \pm 0,58 \mathrm{a}$ & $33,700 \pm 0,55 \mathrm{a}$ & $30,230 \pm 0,46 \mathrm{~b}$ \\
\hline
\end{tabular}

Letras minúsculas diferentes na linha diferem estatisticamente $(\mathrm{P}<0,05)$ 
pode ser explicado pelo sistema de produção, exclusivamente em pastagem, e pelo padrão racial desses animais.

Foram encontradas diferenças significativas entre os três cortes para a maioria dos ácidos graxos saturados de cadeia longa. A picanha foi o corte com o maior percentual de ácidos graxos de cadeia longa $(67,92 \%)$ e diferiu significativamente do contrafilé e da costela (65,08 e 65,05\%) (Tabela 3).

O ácido graxo de cadeia longa de maior presença para todos os cortes foi o monoinsaturado oleico (C18:1n-9 cis), que foi encontrado em maior valor no contrafilé $(30,44 \%)$ e na picanha (30,34\%), que apresentou diferença significativa $(\mathrm{P}<0,05)$ em relação à costela $(28,13 \%)$. O teor de ácido oleico (C18:1) é positivamente correlacionado à qualidade sensorial da carne (Melton et al., 1982).

O segundo ácido graxo de maior prevalência foi o esteárico C18:0, encontrado em maior concentração na costela. Este ácido graxo é considerado neutro e no organismo e convertido em ácido oleico (Sinclair, 1993), não influenciando os níveis sanguíneos de colesterol. De todos ácidos graxos, Rodrigues et al. (2004) observaram que o oleico é o de maior concentração na carne de novilhos

Tabela 2 - Composição percentual dos ácidos graxos de cadeia curta e média de diversas marcas de carne bovina

\begin{tabular}{|c|c|c|c|c|c|c|}
\hline \multirow[t]{2}{*}{ Ácido graxo } & \multicolumn{6}{|c|}{ Marca } \\
\hline & A & B & $\mathrm{C}$ & $\mathrm{D}$ & $\mathrm{E}$ & $\mathrm{F}$ \\
\hline C10:0 & $0,048 \pm 0,004$ & $0,049 \pm 0,003$ & $0,056 \pm 0,004$ & $0,040 \pm 0,004$ & $0,048 \pm 0,003$ & $0,048 \pm 0,004$ \\
\hline C12:0 & $0,072 \pm 0,005 \mathrm{ab}$ & $0,070 \pm 0,004 \mathrm{ab}$ & $0,076 \pm 0,004 \mathrm{ab}$ & $0,058 \pm 0,004 b$ & $0,081 \pm 0,004 a$ & $0,078 \pm 0,006 \mathrm{ab}$ \\
\hline C14:0 & $2,35 \pm 0,14 a b$ & $2,59 \pm 0,13 a$ & $2,54 \pm 0,14 a$ & $1,77 \pm 0,14 b$ & $2,46 \pm 0,14 a$ & $2,56 \pm 0,13 a$ \\
\hline C14:0iso & $0,099 \pm 0,009 a b$ & $0,092 \pm 0,008 \mathrm{ab}$ & $0,107 \pm 0,009 a b$ & $0,074 \pm 0,009 b$ & $0,124 \pm 0,008 a$ & $0,131 \pm 0,011 \mathrm{a}$ \\
\hline C15:0 & $0,59 \pm 0,04 a$ & $0,53 \pm 0,03 \mathrm{ab}$ & $0,59 \pm 0,04 a$ & $0,40 \pm 0,04 b$ & $0,64 \pm 0,03 a$ & $0,69 \pm 0,04 a$ \\
\hline C15:0iso & $0,29 \pm 0,02 \mathrm{a}$ & $0,30 \pm 0,02 a$ & $0,33 \pm 0,02 \mathrm{a}$ & $0,18 \pm 0,02 b$ & $0,36 \pm 0,02 a$ & $0,37 \pm 0,02 \mathrm{a}$ \\
\hline C15:0ant & $0,29 \pm 0,02 \mathrm{ab}$ & $0,26 \pm 0,02 \mathrm{bc}$ & $0,31 \pm 0,02 a b$ & $0,16 \pm 0,02 c$ & $0,34 \pm 0,02 a b$ & $0,37 \pm 0,02 \mathrm{a}$ \\
\hline C16:0 & $23,74 \pm 0,52$ & $24,54 \pm 0,46$ & $24,06 \pm 0,50$ & $23,31 \pm 0,50$ & $23,46 \pm 0,45$ & $23,56 \pm 0,63$ \\
\hline C16:0iso & $0,24 \pm 0,02$ & $0,26 \pm 0,02$ & $0,28 \pm 0,02$ & $0,26 \pm 0,02$ & $0,30 \pm 0,02$ & $0,30 \pm 0,03$ \\
\hline C16:1c9 & $3,21 \pm 0,17$ & $3,84 \pm 0,16$ & $3,54 \pm 0,17$ & $3,27 \pm 0,17$ & $3,46 \pm 0,15$ & $3,53 \pm 0,21$ \\
\hline AG curta & $0,048 \pm 0,004$ & $0,049 \pm 0,003$ & $0,056 \pm 0,004$ & $0,040 \pm 0,004$ & $0,048 \pm 0,003$ & $0,048 \pm 0,004$ \\
\hline AG média & $31,44 \pm 0,72$ & $33,20 \pm 0,65$ & $32,39 \pm 0,71$ & $30,04 \pm 0,71$ & $31,08 \pm 0,63$ & $32,21 \pm 0,88$ \\
\hline
\end{tabular}

Letras minúsculas diferentes na linha diferem estatisticamente $(\mathrm{P}<0,05)$.

Tabela 3 - Composição percentual de ácidos graxos de cadeia longa na carne bovina

\begin{tabular}{|c|c|c|c|}
\hline \multirow[t]{2}{*}{ Ácido graxo } & \multicolumn{3}{|c|}{ Corte } \\
\hline & Contrafilé & Costela & Picanha \\
\hline C17:0 & $1,10 \pm 0,03 c$ & $1,39 \pm 0,03 a$ & $1,21 \pm 0,03 b$ \\
\hline C17iso & $0,62 \pm 0,06 b$ & $0,79 \pm 0,05 a$ & $0,81 \pm 0,04 a$ \\
\hline C17:1 & $0,90 \pm 0,03 b$ & $0,89 \pm 0,02 b$ & $1,05 \pm 0,02 \mathrm{a}$ \\
\hline C18:0 & $15,97 \pm 0,54 b$ & $20,93 \pm 0,51 a$ & $16,46 \pm 0,43 b$ \\
\hline C18:1c9 & $30,44 \pm 0,73 a$ & $28,13 \pm 0,69 b$ & $30,34 \pm 0,58 a$ \\
\hline C18:1c11 & $1,95 \pm 0,11$ & $1,92 \pm 0,10$ & $1,88 \pm 0,09$ \\
\hline C18:1c12 & $0,94 \pm 0,06$ & $0,96 \pm 0,06$ & $0,90 \pm 0,05$ \\
\hline C18:1c13 & $0,38 \pm 0,03$ & $0,41 \pm 0,03$ & $0,40 \pm 0,02$ \\
\hline C18:1c15 & $0,08 \pm 0,02 a b$ & $0,14 \pm 0,02 \mathrm{a}$ & $0,06 \pm 0,01 b$ \\
\hline C18:1t16 & $0,25 \pm 0,03$ & $0,27 \pm 0,03$ & $0,26 \pm 0,02$ \\
\hline C18:2t11c15 & $0,04 \pm 0,02 b$ & $0,08 \pm 0,01 a$ & $0,03 \pm 0,01 b$ \\
\hline C18:2 & $3,44 \pm 0,33 b$ & $1,84 \pm 0,31 c$ & $5,22 \pm 0,26 a$ \\
\hline C18:2с9с12 & $2,71 \pm 0,34 b$ & $1,01 \pm 0,32 \mathrm{c}$ & $4,47 \pm 0,27 a$ \\
\hline C18:3n6 & $0,07 \pm 0,02 b$ & $0,14 \pm 0,01 a$ & $0,10 \pm 0,01 b$ \\
\hline C18:3n3 & $0,86 \pm 0,07 b$ & $0,58 \pm 0,07 c$ & $1,26 \pm 0,06 a$ \\
\hline C20:5 & $0,58 \pm 0,07 a$ & $0,10 \pm 0,06 b$ & $0,69 \pm 0,05 a$ \\
\hline C22:1 & $1,47 \pm 0,21 a$ & $0,25 \pm 0,20 b$ & $2,02 \pm 0,16 a$ \\
\hline C22:5 & $1,02 \pm 0,11 \mathrm{a}$ & $0,26 \pm 0,10 b$ & $1,10 \pm 0,09 a$ \\
\hline C22:6 & $0,11 \pm 0,01 a$ & $0,02 \pm 0,01 b$ & $0,12 \pm 0,01 a$ \\
\hline $\mathrm{C} 24: 0$ & $0,24 \pm 0,04 a$ & $0,06 \pm 0,04 b$ & $0,38 \pm 0,04 a$ \\
\hline Ácidos graxos de cadeia longa & $65,08 \pm 0,57 b$ & $65,05 \pm 0,54 b$ & $67,92 \pm 0,45 a$ \\
\hline Total n6a & 3,51 & 1,98 & 5,32 \\
\hline Total n3b & 1,44 & 0,68 & 1,95 \\
\hline Relação n6:n3 & 2,44 & 2,91 & 2,73 \\
\hline
\end{tabular}

Letras minúscula diferentes na linha diferem estatisticamente $(\mathrm{P}<0,05)$.

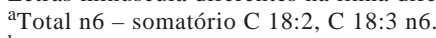

b Total n3 - somatório C 18:3 n3, C 20:5. 
Nelore, pois representa em torno de $88 \%$ dos ácidos graxos monoinsaturados, como observado neste estudo, onde também foi encontrada a maior concentração.

Foram observadas diferenças significativas $(\mathrm{P}<0,05)$ entre os cortes analisados para a os ácidos graxos margárico (C17:0), isomargárico (C17iso), heptadecanóico (C17:1), esteárico (C18:0), oleico (C18:1c9, c11, c12, c13, c15, t16), vaccênico (C18:2trans11cis15), linoleico (C18:2), (C18:2cis9cis12), linolênico (C18:3n3), (18:3n6), eicosapentaenoico (EPA) (C20:5), cetoleico (C22:1), (22:5), docosahexaenoico (DHA) (C22:6) e lignocérico (C24:0). Essas diferenças entre os cortes analisados pode estar relacionada às particularidades de cada grupo muscular, uma vez que o exercício de cada músculo é diferente, assim como os tipos de suas fibras musculares (Lawrie, 2005).

O ácido graxo poliinsaturado mais representativo na carne bovina é o ácido linoleico (C18:2) (Metz et al., 2008). Nesse grupo de ácidos graxos, os ômegas 6 e 3 têm ganhado atenção: busca-se atualmente uma relação menor que 4 entre esses ácidos graxos (DH, 1994). Neste estudo foram encontrados valores adequados para a relação n6:n3 em todos os cortes avaliados.

Entre as seis marcas avaliadas, a D foi a que apresentou o maior percentual de ácidos graxos de cadeia longa (67,93\%) (Tabela 4). O ácido graxo de cadeia longa de com maior presença em todas as marcas foi o monoinsaturado oleico (C18:1n-9 cis), cujos valores, no entanto, não apresentaram diferenças $(\mathrm{P}<0,05)$ entre as marcas. O segundo ácido graxo de maior representatividade foi o C18:0, tendo em vista a diferença significativa $(\mathrm{P}<0,05)$ entre as marcas: a marca $\mathrm{F}$ apresentou o maior percentual desse ácido graxo, diferindo da $\mathrm{B}(19,08 \times 16,10 \%)$.

O ácido esteárico é um componente comum em muitos alimentos, como as carnes vermelhas e os produtos lácteos. Possui muitas características desejáveis de sabor e textura dos ácidos graxos saturados de cadeia longa e geralmente é bastante constante nas carnes bovina, suína, ovina e de vitelo (Allocati et al., 2007). Neste trabalho, os resultados foram semelhantes, pois o ácido esteárico correspondeu de 10 a $12 \%$ do total de ácidos graxos em todas as marcas.

A marca D (oriunda de sistema orgânico) apresentou os maiores percentuais de ácidos graxos considerados essenciais: o linoleico (C18:2 n-6) e o linolênico (C18:3 n-3) (Lawrie, 2005). No sistema orgânico, os animais são terminados a pasto, cuja fração lipídica caracteriza-se por apresentar quantidades elevadas de poliinsaturados. Esta influência da dieta pode ser explicada por Bauman \& Griinari (1999), pois, durante o processo de bio-hidrogenação pela ação de microrganismos ruminais, o ácido linolênico (C18:2, cis9 cis12) passa inicialmente a rumênico (CLA -

Tabela 4 - Composição percentual de ácidos graxos de cadeia longa de carne bovina de diversas marcas

\begin{tabular}{|c|c|c|c|c|c|c|c|}
\hline \multirow[t]{2}{*}{ Ácido graxo } & \multicolumn{7}{|c|}{ Marca } \\
\hline & A & $\mathrm{B}$ & $\mathrm{C}$ & $\mathrm{D}$ & $\mathrm{E}$ & & $\mathrm{F}$ \\
\hline C 17:0 & $1,20 \pm 0,04$ & $1,16 \pm 0,04$ & $1,25 \pm 0,04$ & $1,15 \pm 0,04$ & $1,27 \pm 0,04$ & 1,35 & $\pm 0,05$ \\
\hline C17iso & $0,71 \pm 0,07$ & $0,63 \pm 0,06$ & $0,80 \pm 0,07$ & $0,58 \pm 0,07$ & $0,84 \pm 0,06$ & 0,83 & $\pm 0,08$ \\
\hline C17:1 & $0,91 \pm 0,03$ & $1,02 \pm 0,03$ & $0,91 \pm 0,03$ & $0,94 \pm 0,03$ & $1,00 \pm 0,03$ & 0,96 & $\pm 0,04$ \\
\hline C18:0 & $18,40 \pm 0,63 a b$ & $16,10 \pm 0,57 b$ & $18,50 \pm 0,62 \mathrm{ab}$ & $16,35 \pm 0,62 \mathrm{ab}$ & $17,32 \pm 0,55 a b$ & 19,08 & $\pm 0,77 a$ \\
\hline C18:1c9 & $28,81 \pm 0,89$ & $31,54 \pm 0,80$ & $29,57 \pm 0,86$ & $29,95 \pm 0,86$ & $29,34 \pm 0,77$ & 28,78 & $\pm 1,08$ \\
\hline C18:1c11 & $1,89 \pm 0,13$ & $2,08 \pm 0,12$ & $1,88 \pm 0,13$ & $2,05 \pm 0,13$ & $1,76 \pm 0,12$ & 1,92 & $\pm 0,16$ \\
\hline C18:1c12 & $0,98 \pm 0,08$ & $0,88 \pm 0,07$ & $1,03 \pm 0,08$ & $1,08 \pm 0,08$ & $0,90 \pm 0,07$ & 0,80 & $\pm 0,10$ \\
\hline C18:1c13 & $0,42 \pm 0,04 \mathrm{ab}$ & $0,35 \pm 0,03 a b$ & $0,43 \pm 0,03 a b$ & $0,51 \pm 0,03 a$ & $0,41 \pm 0,03 a b$ & 0,33 & $\pm 0,04 \mathrm{~b}$ \\
\hline C18:1c15 & $0,08 \pm 0,02$ & $0,11 \pm 0,02$ & $0,07 \pm 0,02$ & $0,03 \pm 0,02$ & $0,09 \pm 0,02$ & 0,10 & $\pm 0,03$ \\
\hline C18:1t16 & $0,26 \pm 0,04$ & $0,20 \pm 0,03$ & $0,32 \pm 0,04$ & $0,36 \pm 0,04$ & $0,28 \pm 0,03$ & 0,20 & $\pm 0,04$ \\
\hline C18:2t11c15 & $0,07 \pm 0,02$ & $0,02 \pm 0,01$ & $0,04 \pm 0,02$ & $0,02 \pm 0,02$ & $0,05 \pm 0,01$ & 0,05 & $\pm 0,02$ \\
\hline C18:2 & $3,89 \pm 0,42 \mathrm{ab}$ & $3,24 \pm 0,38 b$ & $3,54 \pm 0,41 b$ & $5,53 \pm 0,41 a$ & $3,89 \pm 0,37 a b$ & 3,41 & $\pm 0,52 b$ \\
\hline C18:2c9c12 & $3,17 \pm 0,44 a b$ & $2,42 \pm 0,39 b$ & $2,85 \pm 0,43 b$ & $5,00 \pm 0,43 a$ & $3,05 \pm 0,38 a b$ & 2,54 & $\pm 0,53 b$ \\
\hline C18:3n6 & $0,11 \pm 0,01$ & $0,07 \pm 0,01$ & $0,12 \pm 0,01$ & $0,07 \pm 0,01$ & $0,11 \pm 0,01$ & 0,10 & $\pm 0,02$ \\
\hline C18:3n3 & $0,93 \pm 0,09 b$ & $0,80 \pm 0,08 b$ & $0,98 \pm 0,09 b$ & $1,41 \pm 0,09 a$ & $0,99 \pm 0,08 a b$ & 0,86 & $\pm 0,11 b$ \\
\hline C20:5 & $0,51 \pm 0,09 a b$ & $0,40 \pm 0,08 a b$ & $0,42 \pm 0,09 a b$ & $0,79 \pm 0,09 a$ & $0,57 \pm 0,08 a b$ & 0,37 & $\pm 0,11 b$ \\
\hline C22:1 & $1,44 \pm 0,27 b$ & $1,06 \pm 0,24 b$ & $1,13 \pm 0,26 b$ & $2,71 \pm 0,26 a$ & $0,53 \pm 0,24 a b$ & 1,03 & $\pm 0,33 b$ \\
\hline C22:5 & $0,93 \pm 0,14 \mathrm{ab}$ & $0,67 \pm 0,12 b$ & $0,71 \pm 0,14 b$ & $1,44 \pm 0,14 a$ & $0,95 \pm 0,12 \mathrm{ab}$ & 0,63 & $\pm 0,17 b$ \\
\hline C22:6 & $0,10 \pm 0,02 \mathrm{ab}$ & $0,06 \pm 0,02 b$ & $0,06 \pm 0,02 b$ & $0,15 \pm 0,02 \mathrm{a}$ & $0,10 \pm 0,01 a b$ & 0,07 & $\pm 0,02 b$ \\
\hline C24:0 & $0,31 \pm 0,06$ & $0,21 \pm 0,05$ & $0,27 \pm 0,06$ & $0,33 \pm 0,06$ & $0,24 \pm 0,05$ & 0,19 & $\pm 0,07$ \\
\hline $\begin{array}{l}\text { Ácidos graxos } \\
\text { cadeia longa }\end{array}$ & $66,89 \pm 0,73$ & $65,35 \pm 0,65$ & $66,22 \pm 0,71$ & $67,93 \pm 0,71$ & $66,29 \pm 0,63$ & 66,26 & $\pm 0,88$ \\
\hline Total n6a & 4,00 & 3,31 & 3,66 & 5,60 & 4,00 & & 3,51 \\
\hline Total n3b & 1,44 & 1,20 & 1,40 & 2,20 & 1,56 & & 1,23 \\
\hline Relação n6:3 & 2,78 & 2,76 & 2,61 & 2,54 & 2,56 & & 2,85 \\
\hline
\end{tabular}

Letras minúscula diferentes na linha diferem estatisticamente $(\mathrm{P}<0,05)$.

aTotal n6 - Somatório C 18:2, C 18:3 n6.

bTotal n3 - Somatório C 18:3 n3, C 20:5. 
C18:2, cis9 trans11), passando depois a ácido vaccênico (C18:1, trans11) e posteriormente a esteárico (C18:0). Esses ácidos graxos são absorvidos pelos animais e alcançam os tecidos. Pela ação da enzima $\Delta^{9}$-desaturase nos tecidos, o ácido esteárico pode ser transformado em ácido oleico (C18:1, cis9) e o ácido vaccênico (C18:1, trans11) pode ser transformado em ácido rumênico. Esta bio-hidrogenação microbiana no rúmen ocorre nos bovinos, pois os ácidos graxos insaturados apresentam toxidez a um grupo de microrganismos ruminais e precisam ser convertidos em ácidos graxos saturados, que são menos prejudiciais a esses microorganismos.

Não houve interação $(\mathrm{P}>0,05)$ entre cortes e marcas para os valores totais de grupos e relações entre ácidos graxos nem para as estimativas dos índices $\Delta^{9}$ desaturase C16 e C18 (Tabela 5).

Observou-se, no entanto, diferença entre cortes $(\mathrm{P}<0,05)$ para todos os ácidos graxos avaliados. A costela apresentou maior grau de saturação de ácidos graxos (53,03\%) em comparação ao contrafilé $(47,28 \%)$ e à picanha $(44,86 \%)$. A maior saturação da costela possivelmente esteve relacionada à quantidade de gorduras (lipídios totais) (De Smet et al. 2004). Valores inversos, no entanto, foram observados para o grau de insaturação dos ácidos graxos, que foi maior na picanha $(53,43 \%)$ e menor na costela (45,92\%) (Tabela 5).

De acordo com Mulvihill (2001), de modo geral, na gordura intramuscular, predominam os ácidos graxos saturados. Neste estudo, a costela apresentou predominantemente gordura saturada, possivelmente em decorrência da maior a quantidade de lipídios totais, extrato etéreo ou gordura na carne (De Smet et al., 2004).
O contrafilé apresentou maior percentual de ácidos graxos monoinsaturado (44,98\%), mas não diferiu da picanha, e a costela foi o corte com a menor composição percentual. Essa diferença encontrada para a costela pode ser explicada pela maior variabilidade nos depósitos de gorduras desse corte (Aldai et al., 2007).

A ingestão de ácidos graxos monoinsaturados traz benefícios à saúde humana, por ocasionar queda nos níveis de colesterol total no plasma sanguíneo (Departament of Health, 1994). Portanto, maiores níveis de AGM são benéficos e neste estudo são representados pelo contrafilé seguido da picanha.

O corte picanha apresentou maior percentual de ácidos graxos poliinsaturados (8,53\%), diferindo do contrafilé (6,11\%) e costela (2,95\%). Essa maior quantidade na picanha possivelmente está relacionada às maiores quantidades de membranas celulares rica em PUFA (De Smet et al., 2004). E a menor quantidade de PUFA no corte costela possivelmente esteja associada a uma maior quantidade de gordura intramuscular, que de acordo com (Wood et al., 2008) descreve que esta é composta principalmente de lipídios neutros.

A picanha demonstrou uma maior relação de ácidos graxos insaturados/saturados do que o contrafilé e a costela $(\mathrm{P}<0,05)$, mesmo resultado encontrado para a relação de ácidos graxos poliinsaturados/saturados. Esses maiores valores médios podem ser explicadas pelos altos percentuais de ácidos graxos insaturados e poliinsaturados encontrados neste corte. De acordo com o Departament of Health (1994) são preconizados para essa relação valores superiores a 0,4 , relacionados a menores riscos de doenças cardiovasculares. É interessante aumentar a proporção

Tabela 5 - Composição percentual de ácidos graxos da carne bovina

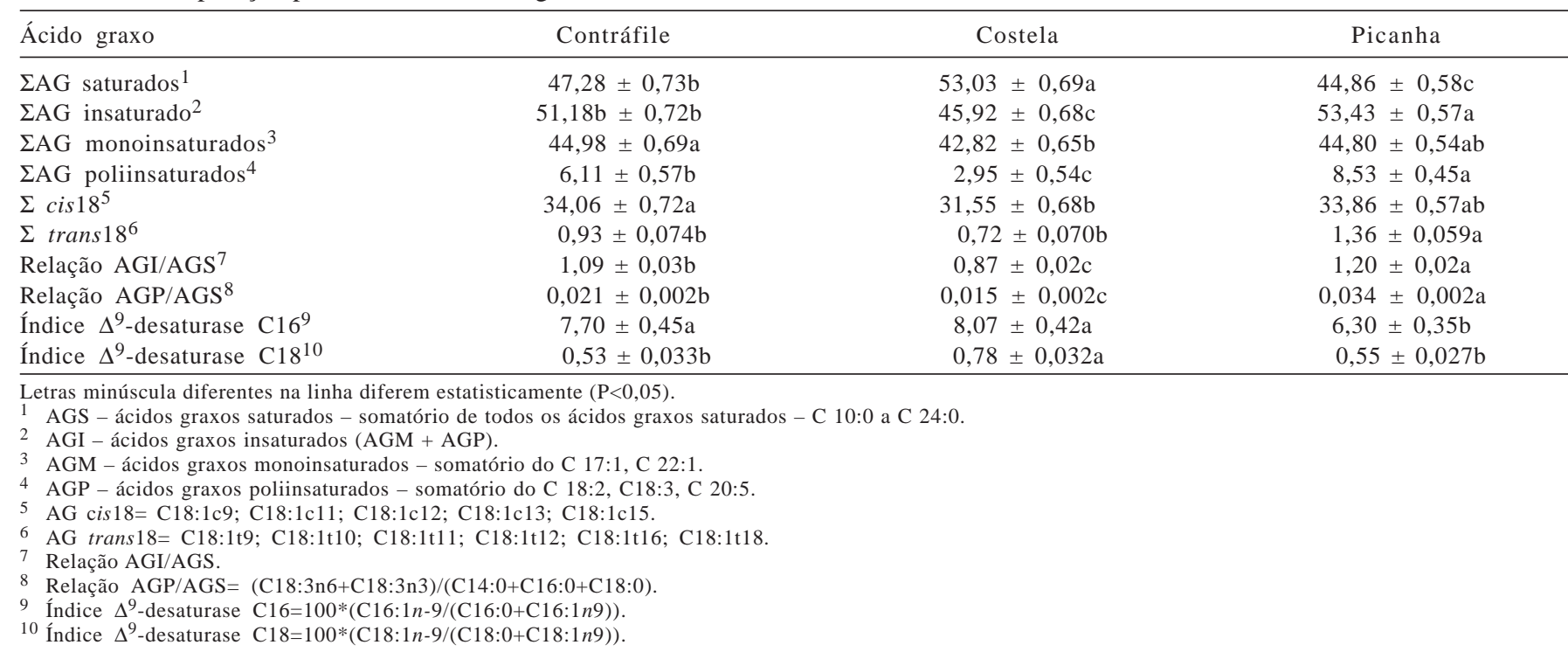


de ácidos graxos insaturados, em especial os ácidos graxos poliinsaturados, pois vários destes estariam relacionados a efeitos positivos à saúde humana (Williams, 2000).

Neste trabalho foram observados valores da relação AGP/AGS bem abaixo do preconizado para todos os cortes avaliados, o que poderia sugerir, que estes cortes são menos saudáveis para o consumo humano.

Os ácidos graxos poliinsaturados mais representativos na carne bovina (em termos de quantidade percentual) são os ácidos linoleico (C18:2) e araquidônico (C20:4) (Metz et al., 2008). Por outro lado, em termos nutricionais, atenção tem sido dada para os ácidos graxos essenciais (ácidos linoléico e ácido linolênico) e os de cadeia longa da classe n-3, como o eicosapentaonoico (C20:5 n-3) e o docosahexaenoico (C22:6n-3) (Williams, 2000).

O corte contrafilé apenas apresentou o maior percentual de cis 18 em relação à costela. O maior percentual de trans18 foi encontrado na picanha (1,36\%), em relação aos outros dois cortes $(\mathrm{P}<0,05)$. Os ácidos graxos insaturados cis e trans se diferenciam, pois o cis apresenta na sua ligação dupla os hidrogênios dispostos de forma transversal, resultado da bio-hidrogenação ruminal. Os ácidos graxos trans são prejudiciais a saúde humana, com excessão do procursor endógeno do CLA, o CLA e alguns isômeros do CLA, cujos efeitos benéficos associados são atividade imunoestimulatória, antimutagênica e antioxidante (Ip, 1997).

Quanto à estimativa da atividade da enzima $\Delta^{9}$-desaturase, pode-se observar que houve diferença entre os cortes estudados, tanto na $\Delta^{9}$-desaturase 16 quanto na $\Delta^{9}$-desaturase 18. A atividade da enzima $\Delta^{9}$-desaturase é encontrada no tecido adiposo e sua atividade promove a formação de ácidos graxos monoinsaturados cis-9 e a formação endógena de CLA, (Hayashi, 2007). No presente estudo, o corte costela apresentou maior atividade da $\Delta^{9}$-desaturase no C18, comportamento semelhante aos AG saturados (C16 e C18), portanto esta maior atividade no corte costela pode estar relacionado ao maior percentual de ácidos graxos saturados, bem como a maior quantidade de lipídeos totais $(3,01)$.

Já para o índice da $\Delta^{9}$-desaturase no C16 maior atividade foi encontrada no músculo contrafilé, mesmo comportamento para o ácido graxo poliinsaturado (C18:1 cis 9), desta forma pode-se justificar e relacionar a atividade desta enzima com o metabolismo e o que foi depositado nos diferentes grupos musculares.

Uma adequada relação n6:n3, inferior a 4, foi encontrada para todas as marcas e cortes avaliados. A diferença no total de ácidos graxos saturados e insaturados mais evidente foi nas marcas $\mathrm{C}$ e F que apresentaram maior grau de saturação nos ácidos graxos observado em relação à marca D. Por outro lado, a marca D (53,38\%) apresentou maior índice de insaturação apenas em relação à marca F (49,05\%).

Cruz et al. (2004) que avaliou novilhos confinados, afirma que os efeitos nutricionais podem desencadear modificações na composição do tecido adiposo e dietas oriundas de animais confinados, com alta percentagem de grãos, apresentam na gordura de marmorização, de 45 a $49 \%$ de ácidos graxos insaturados. Portanto, os valores obtidos neste trabalho encontram-se próximos aos obtidos por este autor embora nem todas as marcas tenham origem de animais alimentados com grãos.

Andrae et al. (2001) associaram o alto teor de lipídios totais com maior percentual de ácidos graxos insaturados, entretanto, neste estudo não foi encontrada esta relação, pois a marca com maior teor de lipídios totais foi a B (4,61\%),

Tabela 6 - Composição percentual e erro padrão dos ácidos graxos (AG) da carne de acordo com a marca (\%)

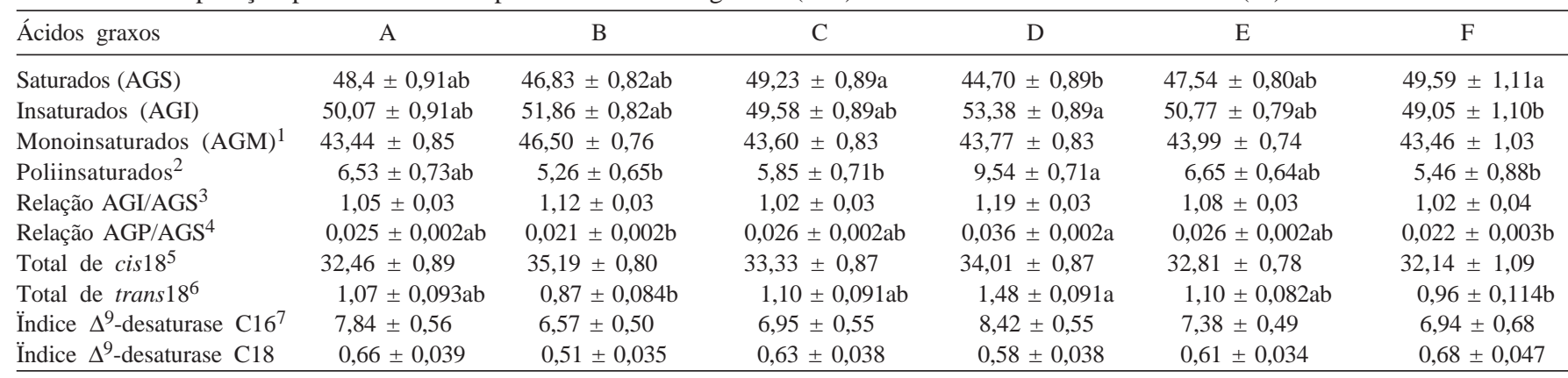

Letras minúscula diferentes na linha diferem estatisticamente $(\mathrm{P}<0,05)$.

${ }_{1}^{1}$ AGM - ácidos graxos monoinsaturados - somatório do C 17:1, C 22:1.

2 AGP - ácidos graxos poliinsaturados - somatório do C 18:2, C18:3, C 20:5.

3 Relação AGI/AGS.

${ }^{4}$ Relação AGP/AGS $=(C 18: 3 n 6+C 18: 3 n 3) /(C 14: 0+C 16: 0+C 18: 0)$.

${ }^{5}$ AG cis18= C18:1c9; C18:1c11; C18:1c12; C18:1c13; C18:1c15.

${ }^{6}$ AG trans18= C18:1t9; C18:1t10; C18:1t11; C18:1t12; C18:1t16; C18:1t18

7 Índice $\Delta^{9}$-desaturase C16 $=100 *(\mathrm{C} 16: 1 n-9 /(\mathrm{C} 16: 0+\mathrm{C} 16: 1 n 9))$.

8 Índice $\Delta^{9}$-desaturase C18 $=100 *(\mathrm{C} 18: 1 n-9 /(\mathrm{C} 18: 0+\mathrm{C} 18: 1 n 9))$. 
enquanto o maior teor de ácidos graxos insaturados foi encontrado na marca D (53,38\%). Esta apresentou maior percentual de ácidos graxos poliinsaturados (9,54\%) diferindo da marca B, F e C. Ela é originada do sistema uruguaio de produção, portanto a dieta destes animais é exclusivamente a base de volumoso, o que pode aumentar a concentração de ácidos graxos poliinsaturados e também podem desencadear relações apropriadas de n-6/n-3 (Latimori et al., 2008).

A relação de ácidos graxos poliinsaturado/saturados (AGP/AGS) foi maior na marca D, diferindo da B, C e F. Smet et al. (2004) relataram que a relação de AGP/AGS diminuiu à medida que aumenta a percentagem de gordura intramuscular até um ponto de estabilização.

Nas raças com maior deposição de gordura, a proporção pode reduzir até 0,05 , enquanto, em raças mais magras, especialmente em músculos duplos, pode ultrapassar valores de 0,5. Essa é a provável explicação para os baixos níveis encontrados nas diferentes marcas avaliadas, pois provavelmente eram oriundas de raças britânicas, reconhecidamente com poder potencial para depositar gordura intramuscular.

De acordo com Di Marco et al. (2007), é aconselhável restringir o consumo de energia proveniente de ácidos graxos saturados a $10-15 \%$ do total de energia consumida na dieta, mantendo-se uma relação AGP/AGS, considerada adequada, de aproximadamente 0,5 , que é muito superior aos valores obtidos em todas as marcas analisadas neste experimento.

Comparando sistemas semelhantes ao deste estudo entre a marca C (sistema convencional) e a D (sistema orgânico) do Uruguai, Gil (2003) verificou em animais terminados a pasto melhor relação entre ácidos graxos poliinsaturados/saturados que naqueles terminados em confinamento. Neste estudo essa relação foi bastante inferior, pois a maior quantidade foi encontrada para a carne do sistema orgânico em relação ao convencional. É provável que as outras marcas sejam oriundas de animais que receberam algum tipo de complementação alimentar com concentrado durante a engorda.

O maior percentual de trans18 foi encontrado para a marca D (1,48\%), diferindo da B (0,87\%). Pode-se inferir com isso que as tabelas nutricionais apresentadas na rotulagem não condizem com a realidade, pois os valores observados nas marcas avaliadas apresentam diferenças no percentual de gordura trans. Alguns estudos comprovam que as relações de consumo de gordura, principalmente do tipo trans, são verdadeiras para alimentos de origem vegetal, mas não para gorduras de origem animal (Hayashi, 2007), fato observado também neste estudo.
A atividade da enzima $\Delta^{9}$-desaturase não apresentou diferença entre as marcas estudadas.

Houve interação entre marca e corte para a porcentagem de CLA C18:2c9t11 (Tabela 7). Na determinação do CLA, a marca D foi excluída da análise, pois foram encontrados problemas nas amostras de contrafilé e costela. O ácido linoleico conjugado (CLA) é um ácido graxo poliinsaturados resultante da bio-hidrogenação incompleta no rúmen dos lipídios insaturados da dieta. É uma mistura de isômeros do ácido linoleico; desses isômeros, a forma C18:2 cis-9 trans11 é a mais encontrada na carne de ruminantes e sua importância decorre de seus vários efeitos na saúde já relatados pela literatura.

Na costela da marca A, foi obtido o maior percentual de CLA. No contrafilé, no entanto, o maior percentual de CLA foi observado na marca $\mathrm{F}$, que diferiu das marcas $\mathrm{A}$ e $\mathrm{E}$ $(0,99 \times 0,63$ e $0,53 \%)$.

Diversos fatores, como alimentação e raça, podem ter influenciado as médias de CLA, pois afetam as deposições de ácidos graxos, entre eles o CLA (French et al., 2003). A diferença nos teores de CLA da costela pode estar relacionada ao fato de que o conteúdo de fosfolipídios e a proporção entre ácidos graxos C18 (CLA) e C16 difere entre os músculos. Pesquisas comprovam que o músculo diafragma, cuja constituição anatômica de fibras musculares se assemelha à dos músculos intercostais, apresenta maior deposição de CLA em comparação ao longissimus e psoas (Lawrie, 2005).

O consumo de carne e leite proveniente de animais ruminantes constitui a principal fonte natural de CLA para o homem (Allocati et al., 2007).

Tabela 7 - Composição percentual dos ácidos graxos C18:2c9t11 de carne bovina de várias marcas comerciais

\begin{tabular}{ccccc}
\hline Marca & \multicolumn{4}{c}{ Corte } \\
\cline { 2 - 4 } & Contrafilé & Costela & Picanha & Média \\
\hline A & $0,53 \pm 0,09 \mathrm{bB}$ & $0,87 \pm 0,11 \mathrm{~A}$ & $0,61 \pm 0,08 \mathrm{~B}$ & 0,67 \\
$\mathrm{~B}$ & $0,86 \pm 0,09 \mathrm{ab}$ & $0,76 \pm 0,08$ & $0,74 \pm 0,08$ & 0,79 \\
$\mathrm{C}$ & $0,66 \pm 0,10 \mathrm{ab}$ & $0,54 \pm 0,09$ & $0,73 \pm 0,09$ & 0,64 \\
$\mathrm{E}$ & $0,63 \pm 0,08 \mathrm{~b}$ & $0,90 \pm 0,08$ & $0,81 \pm 0,08$ & 0,78 \\
F & $0,99 \pm 0,16 \mathrm{a}$ & $0,65 \pm 0,10$ & $0,86 \pm 0,08$ & 0,83 \\
Média & 0,73 & 0,74 & 0,75 & \\
\hline
\end{tabular}

Letras minúscula diferentes na coluna diferem estatisticamente $(\mathrm{P}<0,05)$. Letras maiúsculas diferentes na linha diferem estatisticamente $(\mathrm{P}<0,05)$.

\section{Conclusões}

As características da gordura intramuscular da carne bovina dependem do corte e da marca comercial. A costela é o corte com maior grau de saturação, enquanto a picanha apresenta predominantemente gorduras insaturadas e poliinsaturadas e maiores níveis de gordura trans. A carne 
oriunda do sistema de produção orgânico (marca D) possui menor grau de saturação, ainda que seus níveis de gordura trans sejam mais elevados. A gordura intramuscular do corte picanha tem maiores percentuais de ácidos graxos de cadeia longa, como o C18:1, C18:2 e C18:3, benéficos para o homem. Já a costela tem maiores teores de ácidos graxos de cadeia média considerados nocivos, como o C14 e C16, por outro lado, tem maiores teores de CLA.

\section{Referências}

ALDAI, N.; NAJERA, A.I.; DUGAN, M.E.R. et al. Characterisation of intramuscular, intermuscular and subcutaneous adipose tissues in yearling bulls of different genetic groups. Meat Science, v.76, p.682-691, 2007.

ALLOCATI, P.A.; CABONA, E.; PUHL, L. et al. Impacto del proceso de pasteurizacion $72^{\circ} \mathrm{C} 15$ seg sobre el contenido de isômeros conjugados del ácido linoleico (CLA) em leche cruda bovina. Revista Argentina de Producción Animal, v.27, n.3, p.189-195, 2007.

ANDRAE, J.G.; DUCKETT, S.K.; HUNT, C.W. et al. Effects of feeding high-oil corn to beef steers on carcass characteristics and meat quality. Journal of Animal Science, v.79, p.582-588, 2001.

BANSKALIEVA, V.; SAHLU, T.; GOETSCH, A.L. Fatty acid composition of goat muscles and fat depots: a review. Small Ruminant Research, v.37, n.3, p.255-268, 2000.

BAUMAN, D.; GRIINARI, J.M. Biosynthesis of CLA and its incorporation into meat and milk of ruminants. Journal of Dairy Science, v.77, n.1, p.117, 1999.

BEORLEGUI, C.B. Cambios en el perfil de ácido grasos en productos animales en relación con la alimentación animal y humana. Importancia del ácido linoleico conjugado. 1. Rumiantes. In: CURSO DE ESPECIALIZACION FEDNA, 20., 2004, Barcelona. Anais... Barcelona: FEDNA, 2004. p.79.

CRUZ, G.M.; TULliO, R.R.; ESTEVES, S.N. et al. Peso de abate de machos não-castrados para a produção do bovino jovem. 2. Peso, idade e características da carcaça. Revista Brasileira de Zootecnia, v.33, n.3, p.646-657, 2004.

DI MARCO, O.N.; BARCELLOS, O.J.; COSTA, E.C. Crescimento de bovinos de corte. Porto Alegre: UFRGS, 2007. 276p.

DEPARTAMENT OF HEALTH. Nutritional aspects of cardiovascular disease -16 Report on Health and Social Subjects. London: HMSO, 1994. n. 46.

DE SMET, S.; RAES, K.; DEMEYER, D. Meat fatty acid composition as affected by fatness and genetic factors: a review. Animal Research, v.53, p.81-98, 2004.

FRENCH, P.; STANTON, C.; LAWLESS, F. et al. Fatty acid composition, including conjugated linolenic acid, of intramuscular fat from steers offered grazed grass, grass silage or concentratebased diets. Journal of Animal Science, v.78, p.2849-2855, 2000.

FRENCH, P.; O'RIORDAN, E.G.; MONAHAN, F.J. et al. Fatty acid composition of intra-muscular triacylglycerols of steers fed autumn grass and concentrates. Livestock Production Science, v.81, p.307-317, 2003.
GIL, A. Efeito do sistema de produção sobre a qualidade da carne bovina. In: SIMPÓSIO INTERNACIONAL DA CARNE BOVINA: DA PRODUÇÃO AO MERCADO CONSUMIDOR, 2003, São Borja. Anais... São Borja, 2003. p.119-140.

HARA, A.; RADIN, N.S. Lipid extraciton of tissues with low-toxicity solvent. Analitical Biochemistry, v.90, p.420-426, 1978.

HAYASHI, A.; MEDEIROS, S.R.; CARVALHO, M.H. et al. Conjugated linoleic acid (CLA) effects on pups growth, milk composition and lipogenic enzymes in lactating rats. Journal of Dairy Research, v.74, p.160-166, 2007.

INFORMA ECONOMICS - FNP. Anualpec 2008: Anuário da Pecuária Brasileira. São Paulo: Instituto FNP, 2008. 420p.

INTERNACIONAL COMMITTEE ON VETERINARY GROSS ANATOMICAL NOMENCLATURE - ICVGAT. [2005]. Nomina Anatomica Veterinary. 5.ed. 166p. Disponível em: $<$ http://www.wava-amav.org/Downloads/nav_2005.pdf >. Acesso em: 13/8/2008.

IP, C. Review of the effects of trans fatty acids, oleic acid, n-3 polyunsaturated fatty acids, and conjugated linoleic acid on mammary carcinogenesis in animals. American Journal of Clinical Nutrition, v.66, p.1523-1529, 1997.

LATIMORI, N.J.; KLOSTER, A.M.; GARCÍA, P.T. et al. Diet and genotype effects on the quality index of beef produced in the Argentine Pampeana region. Meat Science, v.79, p.463-469, 2008.

LAWRIE, R.A. Ciência da carne. 6.ed. Porto Alegre: ARTMED, 2005. 384p.

MELTON, S.L.; AMIRI, M.; DAVIS, G.W. et al. Flavor and chemical characteristics of ground beef form grass-, forage-grain- and grain-finished steers. Journal of Animal Science, v.55, n.1, p.77-87, 1982.

METZ, P.M.; MENEZES, L.F.G.; SANTOS, A.P. et al. Perfil de ácidos graxos na carne de novilhos de diferentes categorias e grupos genéticos, terminados em confinamento. Revista Brasileira de Zootecnia, v.38, n.3, p.523-531, 2009.

MULVIHILL, B. ruminant meat as a source of conjugated linoleic acid (CLA). British Nutrition Foundation Nutrition Bulletin, v.26, p.295-299, 2001.

NUERNBERG, K.; DANNENBERGER, D.; NUERNBERG, G. et al. Effect of a grassbased and a concentrate feeding system on meat quality characteristics and fatty acid composition of different cattle breeds. Livestock Production Science, v.94, p.137-147, 2005.

RODRIGUES, V.C.; BRESSAN, M.C.; CARDOSO, M.G. et al. Ácidos graxos na carne de búfalos e bovinos castrados e inteiros. Revista Brasileira de Zootecnia, v.33, p.434-443, 2004.

SINCLAIR, A.J. Dietary fat and cardiovascular disease: the significance of recent developments for the food industry. Food Australia, v.45, p.226, 1993.

SMET, S.; RAES, K; DEMEYER, D. Meat fatty acid composition as affected by fatness and genetic factors: a review. Animal Research, v.53, p.81-98, 2004.

STATISTICAL ANALYSIS SYSTEMS - SAS. User's guide: Version 9.1, Cary: 2002. v.2, 1052p.

WILLIAMS, C.M. Dietary fatty acids and human health. Annales Zootechnie, v.49, p.165-180, 2000.

WOOD, J.D.; ENSER, M.; FISHER, A.V. et al. Fat deposition, fatty acid composition and meat quality: a review. Meat Science, v.78, p.343-358, 2008 